\title{
Mobilidades Urbanas, Espaços Públicos e Manifestações Populares: uma análise dos protestos ocorridos na cidade de Belo Horizonte entre 2012 e $2015^{1}$
}

\section{Laise Hasz ${ }^{2}$}

Centro de Estudos Urbanos (CEURB)/UFMG, Brasil

laise.hasz@hotmail.com

Lucas Nigri ${ }^{3}$

Centro de Estudos Urbanos (CEURB)/UFMG, Brasil

lucasnveloso@gmail.com

Recibido: 4 de febrero de 2017

Aceptado: 20 de agosto de 2017

Disponible en línea: 30 de junio de 2018

\footnotetext{
Artigo de investigação científica e tecnológica, que realiza uma análise quantitativa e qualitativa sobre protestos e manifestações coletivas. Parte do trabalho "Manifestações públicas e mobilidades urbanas: um estudo comparado entre Belo Horizonte e Rio de Janeiro", apresentado no congresso XXXIV International Congress of The Latin American Studies Association, em 2015 na cidade de Nova York (NY), no painel intitulado "Políticas públicas de movilidad urbana: la construcción social de las intervenciones en movilidad en América Latina: participación y práticas ciudadanas".

2 Bolsista de Iniciação Científica FAPEMIG no Centro de Estudos Urbanos (CEURB)/UFMG, graduanda em Ciências Sociais/UFMG (Brasil).

3 Bolsista de Iniciação Científica do Programa de Educação Tutorial (PET/Gov.Federal), pesquisador no Centro de Estudos Urbanos (CEURB)/UFMG, graduando em Ciências Sociais/UFMG (Brasil).
} 


\title{
Movilidades urbanas, espacios públicos y manifestaciones populares: un análisis de las protestas ocurridas en la ciudad de Belo Horizonte entre 2012 y 2015
}

\section{Resumen}

El presente artículo realiza un análisis de las protestas y manifestaciones populares que ocurrieron en la ciudad de Belo Horizonte, entre 2012 y 2015, teniendo como base teórica el nuevo paradigma de las movilidades. A través de un análisis cuantitativo y cualitativo de 323 noticias y reportajes, primero se verificó la composición y la intensidad de las motivaciones de la protesta que reivindican el derecho, el acceso y la calidad de la movilidad urbana. En un segundo momento, se evidenció cómo los espacios de movilidad y el propio movimiento de los cuerpos presentes en los eventos de las noticias son fundamentales en la composición de repertorios performáticos de grupos de manifestantes. Los resultados encontrados demuestran que la movilidad urbana no es solo una agenda política compleja y de extrema relevancia, sino que el mismo acto de movilizarse y/o de interrumpir el flujo de movimiento de la ciudad son estrategias fundamentales en la búsqueda de visibilidad y divulgación de los cuestionamientos políticos en el escenario público.

Palabras clave: movilidad urbana; espacio público; manifestaciones; política; sociología urbana

\section{Urban mobilities, public spaces and public demonstrations: an analysis of the protests ocurred in Belo Horizonte between 2012 and 2015}

\begin{abstract}
This paper analyzes the protests and popular demonstrations that took place in the city of Belo Horizonte between 2012 and 2015, having as theoretical background the new mobility paradigm. Through a quantitative and qualitative analysis of three hundred and twenty three journal articles and reports, firstly we verify he composition and intensity of the protest motives that claim the right, access and quality of urban mobility. In a second moment, it was shown how the spaces of mobility and the movement of the bodies present in those events are fundamental in the composition of performative repertoires of political groups. Our finds show that urban mobility is not only a complex and extremely important political agenda, but that the very act of moving and / or interrupting the flow of movement of this city are fundamental strategies in the search for visibility and dissemination of political challenges on the public scene.
\end{abstract}

Keywords: urban mobility; public space; protests; politics, urban sociology

\section{Mobilidades Urbanas, Espaços Públicos e Manifestações Populares: uma análise dos protestos ocorridos na cidade de Belo Horizonte entre 2012 e 2015}

\section{Resumo}

O presente artigo realiza uma análise de protestos e manifestações populares que ocorreram na cidade de Belo Horizonte, entre 2012 e 2015, tendo como embasamento teórico o novo paradigma das mobilidades. Através de uma análise quantitativa e qualitativa de trezentas e vinte três notícias e reportagens, primeiramente verificou-se a composição e a intensidade das motivações de protesto que reivindicam direito, acesso e qualidade da mobilidade urbana. Num segundo momento, evidenciou-se como os espaços de mobilidade e o próprio movimento dos corpos presentes nos eventos noticiados são fundamentais na composição de repertórios performáticos de grupos protestantes. Os resultados encontrados demonstram que a mobilidade urbana não é apenas uma agenda política complexa e de extrema relevância, mas que o próprio ato de se movimentar e/ou de interromper o fluxo de movimento da cidade são estratégias fundamentais na busca pela visibilidade e divulgação de questionamentos políticos na cena pública.

Palavras-chave: mobilidade urbana; espaço público; manifestações; politica; sociologia urbana 


\section{Introdução}

A agenda politica e os protestos pela mobilidade urbana no Brasil apresentam-se à cena pública com uma intensidade cada vez maior. Tal situação pode ser verificada principalmente nas chamadas "Jornadas de Junho de 2013" brasileiras. Em seu epicentro, manifestações acerca da redução dos custos de transporte público atuaram como catalisadores de um dos maiores ciclos de luta política da história do país. Entretanto, a interseção entre política e mobilidade urbana se encerra somente nestes eventos? Mais importante: a mobilidade urbana é somente uma questão de agenda política?

O presente artigo realiza uma análise de protestos e manifestações coletivas que ocorreram na cidade brasileira de Belo Horizonte, mapeando como tais fenômenos políticos se articulam com noções e preceitos teóricos do novo "paradigma das mobilidades". Para atingir tal objetivo, procura-se considerar como as próprias dinâmicas de mobilidade se apresentam não apenas como motivações de protestos, mas como repertórios performativos de atos coletivos de contestação popular. O trabalho se justifica tanto pela ausência de análises empíricas sobre protestos e manifestações políticas no Brasil para além das Jornadas de Junho de 2013, quanto pelo enfoque dado as mobilidades como variável fundamental para o acontecimento de tais eventos.

Do ponto de vista teórico, o artigo está assentado principalmente na produção acadêmica de alguns representantes da chamada "virada das mobilidades". A mobilização de tal arcabouço permitiu, primeiramente, construir a hipótese de que uma agenda política de mobilidade urbana varia segundo as definições de mobilidade, identidades coletivas e relações de poder que atravessam os atos de deslocamento num dado contexto. Segundo, que as mobilidades urbanas não são apenas uma questão relevante para agentes que almejam a maximização dos fluxos de deslocamento. Diferentes agentes, que articulam espaços e equipamentos de mobilidade segundo repertórios específicos, permitem a composição de múltiplas e ricas performances de resistência e contestação política, sendo 
por este motivo as mobilidades importantes variáveis em estudos sobre protestos e manifestações coletivas.

Empiricamente, para testar tais afirmativas, o artigo apresenta dois eixos de investigação: a) Mobilidades urbanas como agenda política em protestos; b) Dinâmicas de mobilidades como repertório e estratégia política em protestos. Tendo em vista a opção por realizar uma análise histórico-processual, o objeto de análise foi construído a partir de dados coletados em 323 notícias e reportagens sobre manifestações coletivas que ocorreram na cidade de Belo Horizonte, no Brasil, entre os anos de 2012 e 2015. Pela natureza do material hemerográfico selecionado, optou-se por realizar uma categorização e análise estatística dos dados coletados, elucidando os resultados a partir de breves análises qualitativas. Também é apresentada uma análise espacial dos dados em software GIS, permitindo evidenciar como espaços de mobilidade são articulados estrategicamente nestes eventos.

\section{Mobilidade urbana como agenda politica: As "Jornadas de Junho" brasileiras e o novo "paradigma" das mobilidades}

A mobilidade urbana no Brasil se apresenta como uma das principais agendas de protestos políticos nos últimos anos. Esta questão adquiriu extrema relevância popular e midiática no país principalmente a partir do advento das chamadas Jornadas de Junho de 2013. Como um conjunto complexo de acontecimentos políticos que levou milhões de pessoas às ruas brasileiras ao longo de um mês, é principalmente definida por seus estudiosos por sua grande multiplicidade de eventos, agentes e agendas (Gohn, 2013). Dentre estas, destacam-se temáticas como a corrupção, o sistema político brasileiro (representantes, partidos e regras), a melhoria de serviços públicos e o direito à cidade (Nobre, 2013; Ricci y Arley, 2004). Não obstante, em meio a esta complexidade de interesses e demandas, a motivação catalisadora deste ciclo de protestos foram os atos 
políticos contra o aumento da tarifa de transportes que ocorreu na cidade de São Paulo. Neste sentido, a mobilidade urbana poderia ser encontrada no epicentro desse novo ciclo de protestos que emergiu em 2013 (Judensnaider, Lima, Pomar y Ortellado, 2013).

Dentre os diversos trabalhos que afirmam a centralidade da questão da mobilidade urbana nos acontecimentos políticos de Junho de 2013, destaca-se o trabalho de Singer (2013). O autor corrobora a tese de que a emergência destes eventos se deu no protesto protagonizado pelo Movimento Passe Livre (MPL) contra o aumento do custo das tarifas de transporte público, na cidade de São Paulo, no dia 06. A partir da divulgação midiática da violenta repressão policial que ocorrera nessa ocasião, uma proliferação de manifestações se iniciaria por todo o Brasil. Através das mídias e das redes sociais, mais de cem cidades brasileiras organizaram seus próprios protestos em solidariedade com os acontecimentos paulistanos, expondo também sua insatisfação para com as próprias condições de mobilidade urbana nos seus contextos. Dentre estes destacam-se as localidades sede da Copa das Confederações e Copa do Mundo de Futebol Fifa, como as capitais Rio de Janeiro e Belo Horizonte. Não obstante, pontua Ortellado (2013, p. 235), "quando o aumento da passagem foi revogado [...], a difusão da pauta se apoderou de vez do processo", originando assim um desdobramento complexo de conflitos politicos que instaurariam um novo ciclo de protestos no país.

Apesar do acordo sobre a centralidade da pauta da mobilidade urbana nos protestos ocorridos em 2013, poucos trabalhos se propõem a analisar a mobilidade urbana como agenda política em outros contextos e períodos do Brasil. Uma exceção foi encontrada em Cardoso e Di Fátima (2013). Primeiramente, contrariando a tese de que as Jornadas de Junho foram um evento inesperado, os autores consideram que foi um "rompimento de uma bolha de descontentamento historicamente formada no país" (Cardoso e Fátima, 2013, p. 143). Essa mesma situação se aplicaria à pauta política da mobilidade urbana. A afirmativa se justifica pois, antes mesmo da fundação do Movimento Passe Livre em 2005, diversos 
protestos em favor da mobilidade urbana já ocorreram por todo o território nacional. Dentre estes, destacam-se a "Revolta do Buzu" na cidade de Salvador em 2003 e a "Revolta da Catraca" na cidade de Florianópolis em 2004 (Cardoso e Fátima, 2013).

Assim exposto, torna-se claro que a mobilidade urbana é uma agenda política historicamente relevante no país. Não obstante, esta se reduziria à luta por menores custos no transporte público?

A mobilidade urbana é uma temática que atravessa historicamente diversos estudos realizados pelas ciências sociais. Entretanto, novas maneiras de compreender e abordar esta temática foram propostas nos últimos anos. Principalmente a partir dos anos 1990 um "novo paradigma das mobilidades" iniciou-se pelo questionamento de uma definição mecanicista e funcionalista de movimento; esta que constituiu um imaginário coletivo que pouco incentivava estudos sobre a complexidade social e política desta temática (Sheller e Urry, 2006).

Para Cresswell (2006), mobilidade é um conceito atravessado por muitas dimensões e nuances, sendo melhor definido como "movimento contextualizado" ou "socialmente produzido" (Cresswell, 2006, p. 2). Neste sentido, definir mobilidade como um movimento de "um ponto A" para um "ponto B", de forma mecanicista, portanto, não abarcaria toda a complexidade deste fenômeno. Quando se considera que o ato de se movimentar atravessa diversos contextos e comunidades de sentido, atesta-se que este é uma potência de significação, ou seja, uma modalidade ou expressão de "ser no mundo" (p. 3). Ademais, como estados de movimento carregados de conteúdo simbólico, são capazes de expressar significados, narrativas e identidades através de pessoas, objetos ou ideias, estas que se deslocam em diferentes escalas geográficas e campos sociais. Também é um fenômeno atravessado por diversas dinâmicas políticas e relações de poder, tendo em vista custos e constrangimentos socialmente estabelecidos em torno deste ato (p. 10). Neste sentido, as dinâmicas de mobilidade são fundamentalmente atravessadas pela política. Tal afirmativa é corroborada por vários autores que 
questionam e evidenciam disputas e condições sociais de acesso e diferenciação de dinâmicas de movimento (Urry, 2000; Levy, 2001; Cresswell, 2011; Kaufmann, 2014;).

Expostas algumas das características que demonstram a complexidade do conceito de mobilidade urbana, principalmente tendo em vista sua capacidade de produzir identidades como relações de poder, cabe agora compreender como esta temática poderia servir de fundamento para a constituição de uma agenda política específica.

De acordo com Melluci (2001) e Alain Touraine (1984, 1998, 2004), protestos coletivos são fenômenos produzidos por atores sociais que compartilham uma identidade coletiva constantemente construída e renegociada. Um dos principais suportes para esta construção são experiências de marginalidade e opressão compartilhadas por sujeitos que, através de uma rede de solidariedade, agem em busca tanto de recursos materiais como da legitimação de um estilo de vida. Entretanto, tais lutas não ocorrem num plano metafísico, apartadas da materialidade da vida cotidiana. A ação humana é sempre amparada, seja estática ou em movimento. Como afirmam Dooren Massey (2008) e Judith Butler (2015), é no espaço urbano que se estabelecem e coexistem trajetórias de vida, onde se luta por justiça e contra a precariedade, se produzem alianças ou práticas de resistência, num processo político agonístico e em perpetuo movimento. Desse modo, compreender protestos coletivos, suas identidades, alianças e motivações implica verificar as significações e relações que seus protagonistas produzem com os espaços, equipamentos e dinâmicas de mobilidade, tendo em vista que estas são "fonte de produção de novos espaços, de novas identidades, novas relações e diferenças" (Massey, 2008, p. 18) e que "a praça e a rua não são apenas suportes materiais para a ação, mas são em si mesmas parte de qualquer narrativa ou interpretação que possamos porventura propor sobre a ação corporal política" (Butler, 2015, p. 12). 


\section{Mobilidade Urbana e repertório político: movimentos, corpos e espaços em performance}

Para além de realizar um mapeamento da agenda política de mobilidade urbana de um contexto específico, um segundo objetivo deste artigo é compreender de que forma as mobilidades urbanas atravessam e são mobilizadas em atos de contestação popular. Neste sentido, para a construção de um objeto de análise, faz-se necessário compreender tanto as condições de possibilidade das performances politicas de protestos e manifestações coletivas, como as dimensões de mobilidade que podem estar presentes nestas situações.

Com relação a primeira questão, de acordo com Charles Tilly (1995), atos de desafio e manifestação coletiva são fenômenos responsivos a contextos políticos específicos. Mesmo dotados de dinâmica elevada, as estratégias de ação mobilizadas por grupos protestantes não são criações completamente espontâneas. São na maioria das vezes consequência de um processo de seleção realizada a partir de experiências bem-sucedidas anteriores que servem de suporte à construção de um "repertório" de performance política. Esta noção é definida como um conjunto limitado de rotinas aprendidas, compartilhadas e postas em ação por meio de um processo relativamente deliberado de escolha, realizada por grupos que avaliam oportunidades politicas de um contexto. Nesse sentido, em qualquer ponto particular da história, grupos mobilizam um arcabouço performático de protesto limitado, por isso, passivel de observação e análise (Tilly, 1995 apud Tarrow, 2009, p. 26).

Cabe agora refletir sobre possiveis modalidades de movimento e espaços de mobilidade que podem ser elementos constituidores de repertórios de protesto. Um primeiro caminho pode ser encontrado no pensamento de Hayden Lorimer (2011). Corroborando com a tese de que as mobilidades são estados de movimento dotados de significado, a autora afirma que os atores sociais mobilizam diferentes maneiras de se deslocar ou permanecer no espaço segundo diferentes intenções de se expressar. Desse modo, a seleção de maneiras de se locomover podem carregar tanto uma potencialidade artística como 
política de acordo com sua forma de execução e contexto. Variam também em termos de escala, desde performances massivas de resistência ou expressões individuais "criativamente orquestradas" (Lorimer, 2011 , p. 24). Assim sendo, analisar performances e modalidades de movimento conforme apresentados num dado protesto ou manifestação coletiva pode nos informar sobre a participação das mobilidades na construção de repertórios de resistência e enfrentamento.

Outro ponto de reflexão é a participação dos espaços de mobilidade em eventos políticos. Para a autora Filipa Matos Wunderlich (2008), compreender dinâmicas de mobilidade implica verificar a relação que estas possuem com o próprio espaço em que ocorrem. Isto se justifica, tendo em vista que tanto o movimento como as localidades são dotados de sentido e/ou atravessadas por relações de poder, o somatório de suas variáveis podem provocar diferentes resultantes. Assim, ao caminhar por diferentes espaços, atores sociais podem manipular seus atributos singulares de forma a articulá-los como componentes estéticos de seu próprio movimento. Tal proposição corrobora o pensamento de David Harvey (1980) que afirma que as formas espaciais são consequências de forte caráter simbólico das formas do processo social de um dado momento, atuando de maneira determinante nos comportamentos e processos futuros.

É importante ressaltar que o espaço e os diversos aparatos que o compõem e que nele performam não são estáticos ou dados a priori, mas fruto de uma performance e reivindicação política. Para Lefebvre (2008) e Santos (1996), as contradições do espaço e daqueles que nele se movimentam são resultantes do conteúdo prático e social de uma sociedade determinada, pelas contradições e conflitos que se manifestam nesta interação. Mas de que forma tal processo ocorreria? Para Michel de Certeau (1998), "o ato de caminhar está para o sistema urbano como uma enunciação está para a língua ou para os enunciados proferidos" (Certeau, 1998, p. 177). Assim sendo, um percurso de deslocamento não é aleatório, sendo na verdade uma escolha dotada de sentido, intencionalidade e discurso. Não obstante, se movimentar ou permanecer estático nos espaços urbanos envolve a negociação de permissões e proibições. Desta maneira, os atores sociais em movimento podem 
tanto contestar como atualizar as próprias imposições de uma ordem estabelecida ao criar desvios e restrições para outros e para si mesmos, o que promoveria uma verdadeira "retórica ambulatória" (Certeau, 1998, p. 179). O espaço público, portanto, não é algo dado a priori: é resultado de luta entre grupos distintos que disputam, politicamente, uma "esfera de aparecimento" e dependem da articulação de diversas materialidades e espacialidades em suas performances (Butler, 2015). Destarte, analisar a interação entre dinâmicas de mobilidade e espaço público em atos de contestação popular não poderia se limitar a somente identificar como performances e cenários são mobilizados nestes eventos, mas também os efeitos coletivos que os grupos protestantes produzem no fluxo cotidiano de uma dada localidade.

A partir da exposição realizada, espera-se que diferentes modos de mobilidade sejam acionados em performances e manifestações coletivas de acordo com um repertório político de protestos construído por diferentes grupos. Nesse sentido, cabe analisar como dinâmicas de movimento em distintos espaços públicos e vias de mobilidade podem se complementar, se opor e produzir diferentes efeitos de acordo com um contexto específico.

\section{Metodologia de pesquisa}

O presente artigo pretende realizar uma análise de protestos e manifestações coletivas brasileiras, almejando: a) identificar como a composição e a intensidade da agenda politica de mobilidade urbana se apresenta na cidade de Belo Horizonte e suas variações; b) como os espaços de mobilidade urbana e as performances em movimento dos diferentes agentes sociais presentes em protestos e manifestações são importantes variáveis em performances politicas.

Para realizar tal intento, foi selecionado como recorte de pesquisa uma das principais capitais brasileiras, a cidade de Belo Horizonte ${ }^{4}$ no período de 2012 a 2015 . Essa escolha se justifica

\footnotetext{
4 A cidade de Belo Horizonte possui, segundo estimativa para 2016, 2513451 habitantes, em uma área territorial de
} 
pois: a) A cidade de Belo Horizonte foi local de intensas manifestações no contexto das Jornadas de Junho de 2013; b) Foi sede de importantes eventos internacionais como a Copa das Confederações FIFA 2013 e Copa do Mundo de Futebol FIFA 2014 que incentivaram múltiplos protestos pela cidade tendo em vista a oportunidade de visibilidade política; c) Apesar de sua relevância politica e econômica no âmbito brasileiro, ainda é um contexto pouco estudado quando em comparação às cidades como São Paulo e Rio de Janeiro; d) Atualmente, possui diversos movimentos sociais de expressão nacional com alta frequência de mobilização coletiva por melhorias na mobilidade urbana na cidade; e) O recorte temporal realizado permitirá verificar como a agenda política desta cidade se apresentou antes das Jornadas de Junho de 2013 e como foi alterada a partir destes eventos. ${ }^{5}$

A análise foi realizada a partir de 323 notícias e reportagens sobre protestos e manifestações coletivas, de acordo com o recorte anterior, conforme publicadas no periódico Jornal o Tempo. Esta escolha principalmente se justifica tanto pelo foco desta mídia na cobertura de acontecimentos políticos que ocorrem na cidade de Belo Horizonte, pela existência de um acervo organizado e por sua ampla circulação na região. Apesar das possiveis implicações que envolvem a produção deste tipo de narrativa, procurou-se realizar a coleta de dados sem se considerar sentenças que evidenciem o posicionamento ou opinião do veículo, limitando-se a identificar: a) Data e Motivos do protesto; b) Agentes envolvidos; c) Performance e desdobramentos do evento; d) Localização e espacialidade. Ressaltamos que, em muitos dos casos, estas variáveis não foram encontradas em todas as reportagens. Nessas ocasiões, considerou-se, a ausência de uma

$331,401 \mathrm{~km}^{2}$, correspondendo à sexta maior cidade brasileira em número de habitantes. A região metropolitana da cidade é a terceira maior do país, possuindo mais de cinco milhões de habitantes. Fonte: IBGE.

5 Esta seria uma das principais justificativas para se recorrer a análise de material hemerográfico como objeto de estudo. Por um lado, ganha-se uma análise comparativa processual dos fenômenos estudados num dado contexto. Por outro, abdica-se da possibilidade de utilizar outros "métodos móveis", caros aos teóricos da mobilidade contemporânea, tendo em vista que estes fundamentalmente dependem de estudos sincrônicos (em movimento). Também, implica na impossibilidade de entrevistar os protagonistas dos eventos políticos passados e considerar seu ponto de vista. Entretanto, autores como Cresswel (2006) não abdicaram de discutir a "virada da mobilidade" devido a esta opção metodológica ao abordar, por exemplo, a evolução de legislações americanas segundo as concepções de mobilidades dominantes num dado contexto. 
informação como um dado "não informado", evitando assim interpretações ou inferências por nossa parte.

É importante destacar algumas vantagens e desvantagens da fonte de informação utilizada. Como o estudo pretendeu observar os protestos ocorridos na cidade de forma processual, a utilização de um periódico se mostrou a melhor fonte de dados. Também, por permitir identificar por quem, de que forma e como os espaços de mobilidade são articulados pelos protestos, assim com os efeitos destes na cidade. Por outro lado, utilizar apenas um periódico como fonte poderia enviesar a análise com o posicionamento da mídia. Entrementes, mobilizar mais de uma fonte transformaria o trabalho numa comparação de narrativas entre diferentes mídias, não contribuindo de forma concreta para o levantamento de ocorrências na cidade, pois seria dificil garantir que duas notícias publicadas em periódicos diferentes tratam do mesmo acontecimento.

Categorizados os dados, um processamento estatístico foi realizado de forma a verificar a intensidade e a variação dos dados temporalmente. Por fim, para os protestos em que a localidade fora indicada, coordenadas geográficas foram obtidas através do software Google Earth para realização de análise espacial em software GIS, de forma que verificássemos como diferentes espaços são mobilizados politicamente por diferentes protestos e manifestações.

\section{Resultados e discussão}

\section{Mobilidade urbana como agenda de protesto}

A primeira parte dos resultados apresentados se refere a identificação e análise das motivações de protestos conforme noticiadas pelo Jornal o Tempo. Primeiramente, apresentamos um contraste entre a frequência dos protestos que se referem à mobilidade urbana em comparação a outras motivações: 


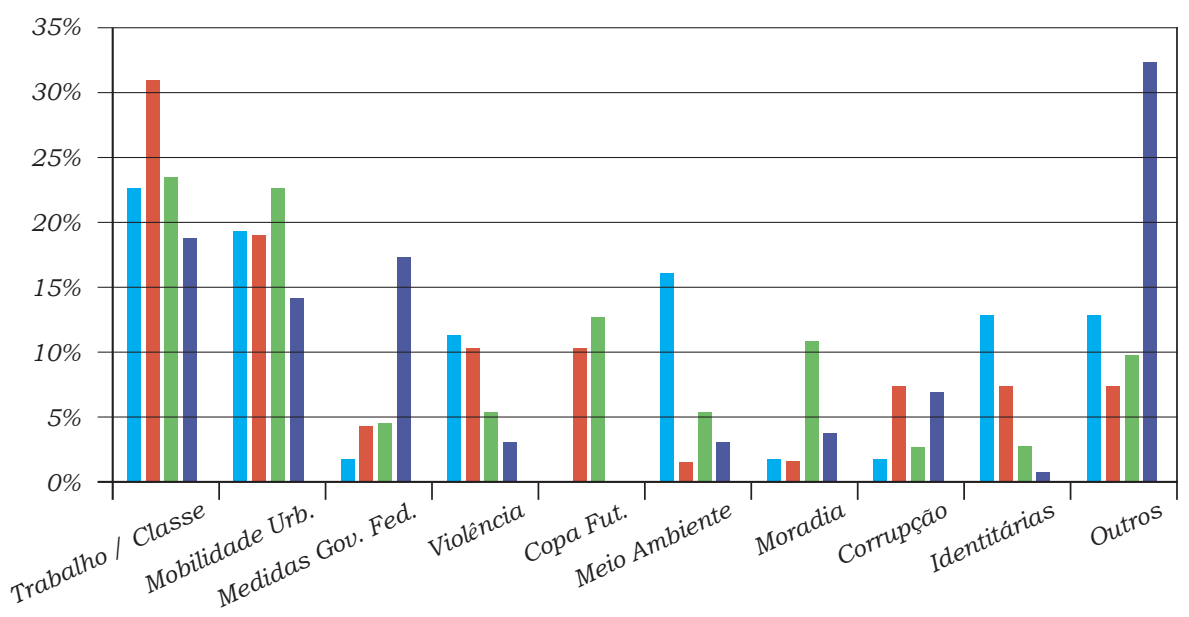

$2012 \square 2013 \square 2014 \square 2015$

Tabela 1. Agenda politica dos protestos de Belo Horizonte entre 2012 e 2015

Fonte: Elaboração própria a partir dos dados coletados no periódico "O Tempo".

Através do gráfico apresentado na Tabela 1, verificou-se como a mobilidade urbana se apresenta como agenda politica de extrema relevância no contexto abordado. Já em 2012 esta temática esteve presente em $19 \%$ dos protestos noticiados; taxa ligeiramente menor do que as mobilizações por melhores salários e condições de trabalho que lideraram neste ano com 23 \% dos eventos.

No ano de 2013, a questão da mobilidade urbana correspondeu a $19 \%$ dos protestos noticiados. A expectativa era que nesse ano houvesse um aumento comparado com o ano anterior tendo em vista sua centralidade nas Jornadas de Junho. Entretanto, verifica-se que esta questão dividiu a cena política deste com diversas outras pautas e demandas populares ("Ruas ocupadas por protesto", 2013), principalmente questionamentos aos investimentos públicos para sediar a Copa do Mundo no Brasil. Eventos que expressaram indignação para com a corrupção e outras medidas do governo federal também se expandiram neste 
contexto político, envolvendo mais de 60 mil manifestantes ("Belo Horizonte tem 20 mil nas ruas", 2013). Ainda em relação a este ano, as demandas por Condições de Trabalho também aumentaram sua presença para $31 \%$.

Em 2014 se atesta o ápice da participação da mobilidade urbana na agenda política dos protestos da cidade, $23 \%$. Em paralelo, a contestação por melhores condições de moradia urbana também se expandiram, alcançando a marca de $11 \%$. Uma ligeira expansão nas manifestações contra a Copa do Mundo de futebol também pode ser verificada graças à oportunidade politica de contestação durante os jogos internacionais que aconteceram na própria cidade ("Jovens voltam as ruas", 2014; "Manifestação pacífica termina", 2014).

Por fim, o ano de 2015 apresenta uma retração nos protestos que abordam o tema da mobilidade urbana na cidade, com indice caindo para $14 \%$. Essa situação se deve também ao próprio contexto político do período, quando medidas e agentes do governo federal tornaram-se os principais alvos das manifestações populares ("Praça tomada por insatisfeitos", 2015). Destacam-se protestos tanto contra e a favor do impeachment da presidente Dilma Rousseff (medidas ou agentes do Governo Federal, $14 \%$ ) como o próprio Partido dos Trabalhadores, Estatais (Petrobrás) e seus membros (outros, $32 \%$ ). Não obstante, as demandas de classe e por melhores condições de mobilidade urbana na cidade ainda permaneceram expressivas neste contexto.

Assim exposto, mesmo que o contexto e as oportunidades políticas influenciem o espectro e a agenda política, a mobilidade urbana demonstrou-se como um motivo mobilizador intenso na cidade de Belo Horizonte. Cabe agora verificar quais são as especificidades da própria agenda dos protestos por mobilidade: 


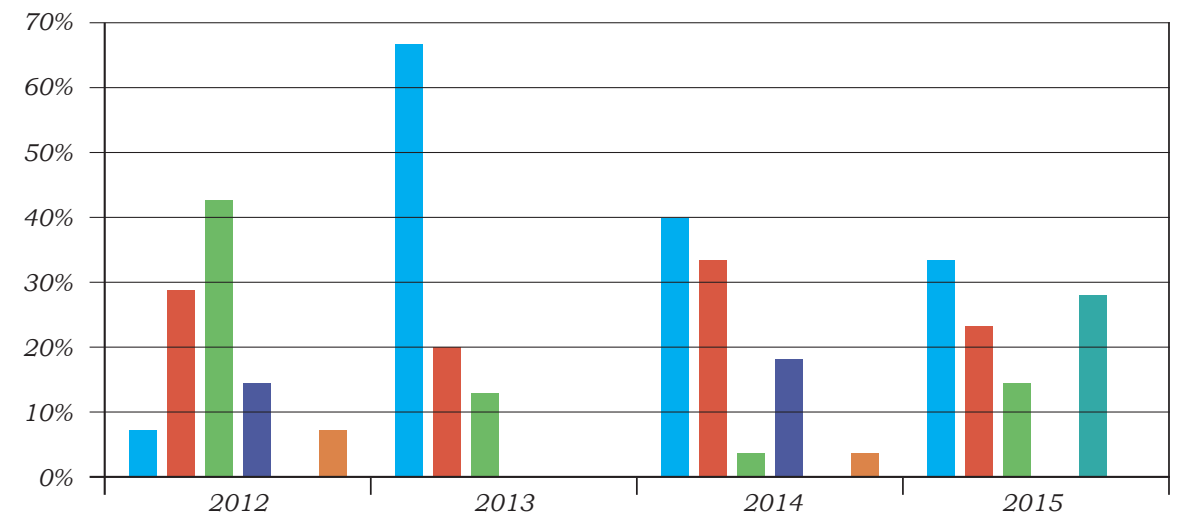

Tabela 2. Composição agenda politica de mobilidade por ano

Fonte: Elaboração própria a partir dos dados coletados no periódico "O Tempo".

Através dos dados expostos, é possível verificar que a agenda de lutas pela mobilidade urbana não se resume à busca por menor custo do transporte público na cidade. Não obstante, essa pauta alcançou seu ápice no ano de 2013, quando presente em $67 \%$ dos protestos. Essa situação se justifica principalmente pelas Jornadas de Junho que ocorreram neste ano. Em 2014 e 2015 registrou-se uma sequência de quedas nos protestos que abordam esta questão.

Paralelamente, constata-se a expressividade das lutas por direito à melhor infraestrutura de transporte alternativo ("Ciclistas organizam protesto", 2014), pelo aumento da qualidade e segurança do transporte público ("Manifestação também na capital", 2015) e contra efeitos ambientais e remoção de pessoas por conta da própria expansão da malha de transporte público da cidade.

Destacamos também a importância de protestos realizados por trabalhadores do setor de transporte em busca de melhores condições de trabalho e aumento de salários ("Ônibus parados na 
segunda", 2012). Esta pauta apresentou seu ápice no ano de 2012 com uma gradativa redução ao longo do tempo (de 43 \% em 2012 para $14 \%$ em 2015). Ademais, em 2015 verificou-se o surgimento de um novo conflito envolvendo a oferta de serviços de mobilidade urbana na cidade. Este foi protagonizado por diversos grupos de taxistas que, visando garantir sua exclusividade, realizaram diversos atos coletivos em oposição ao serviço Uber (Protesto, 2015; Mais violência, 2015).

Assim exposto, verificamos que as lutas pela mobilidade urbana não se compõem exclusivamente pela busca por menores custos de deslocamento pela cidade. As pautas variam principalmente pela importância que as mobilidades possuem tanto para a identidade, estilo de vida e capacidade de ofertar serviços de transporte para os cidadãos.

Tendo em vista a conclusão parcial acima, procurou-se verificar quais grupos ou instituições apresentam-se com maior relevância como protagonistas de protestos por mobilidade urbana na cidade de Belo Horizonte:

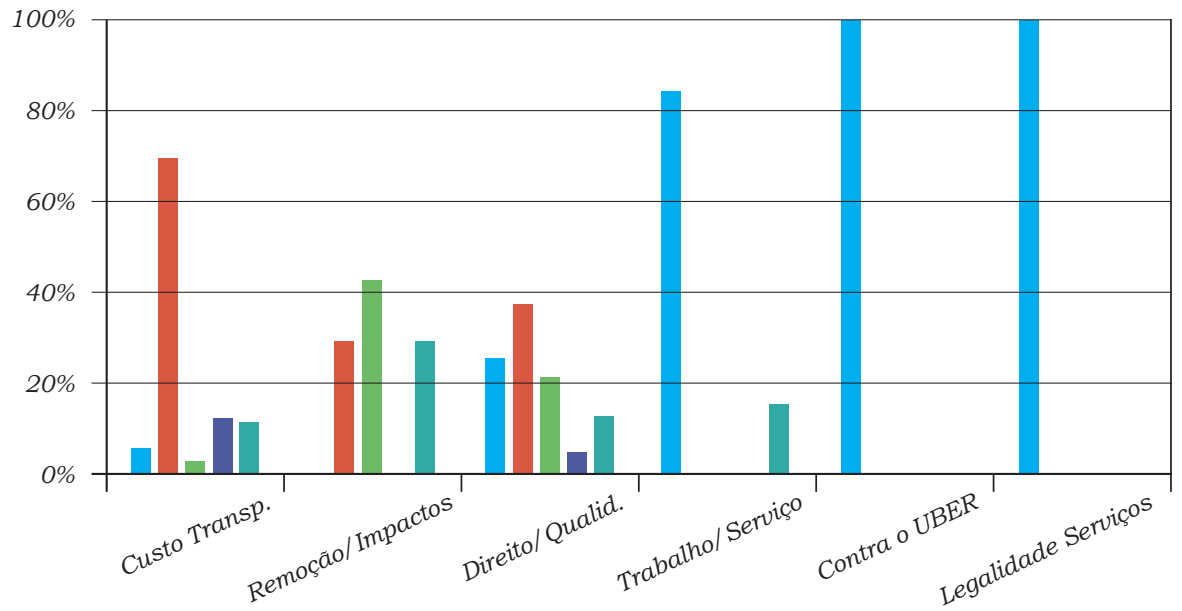

Trab. Serv. Transp. Mov. Sociais Moradores astudantes Outros

Tabela 3. Grupos que protestam por mobilidade e sua relação com a agenda de protesto Fonte: Elaboração própria a partir dos dados coletados no periódico "O Tempo". 
Do ponto de vista dos grupos protestantes, verificamos como a percepção das questões de mobilidade urbana varia segundo os interesses e a identidade construída por atores sociais que partilham interesses em comum. Como é de se esperar, $85 \%$ dos protestos cujas pautas envolvem melhores condições de prestação de serviço de mobilidade urbana são realizados pelos próprios profissionais desse setor. A questão de classe também é bastante expressiva com relação as pautas de legalização do transporte informal e contra a recente controvérsia sobre a legalização dos serviços oferecidos pelo UBER na cidade de Belo Horizonte.

Na luta pela redução dos custos do transporte público na cidade, verifica-se uma participação majoritária de movimentos sociais e estudantis ("Estudantes protestam", 2012). Em Belo Horizonte, o Movimento Tarifa Zero ("Protesto na prefeitura", 2014; "Protesto reúne 400 pessoas", 2015) é identificado pela mídia como o grande protagonista desta pauta.

$\mathrm{Na}$ contestação dos efeitos de obras de expansão da malha de mobilidade na cidade, percebe-se uma menor capacidade de mobilização de distintos grupos da sociedade civil. Esta questão parece ser mais relevante para agentes que compartilhem interesses mais circunscritos geograficamente, como no caso de moradores ou comerciantes de localidades alvo de projetos de mobilidade urbana (Pedro II é fechada, 2014).

\section{Espaços e movimento como estratégia e performance em protestos}

O segundo objetivo do trabalho é compreender como os espaços de mobilidade e o movimento dos corpos que se apresentam em protestos compõem repertórios de ação coletiva mobilizados na cena pública. De forma a verificar a possivel influência da motivação política dos grupos protestantes em sua performance e, tendo em vista o foco do presente trabalho na temática da mobilidade urbana, dividimos os resultados encontrados de acordo às categorias "protesto por mobilidade urbana" e "outros protestos". 
Primeiramente, apresentamos uma distribuição espacial dos protestos que ocorreram na região metropolitana da cidade de Belo Horizonte através de mapa produzido em software GIS. A partir deste, de acordo com uma maior ou menor de proximidade geográfica dos eventos coletados, foram produzidas "manchas de calor" para destacar áreas com maior ou menor intensidade de eventos com espectros de cor distintos:

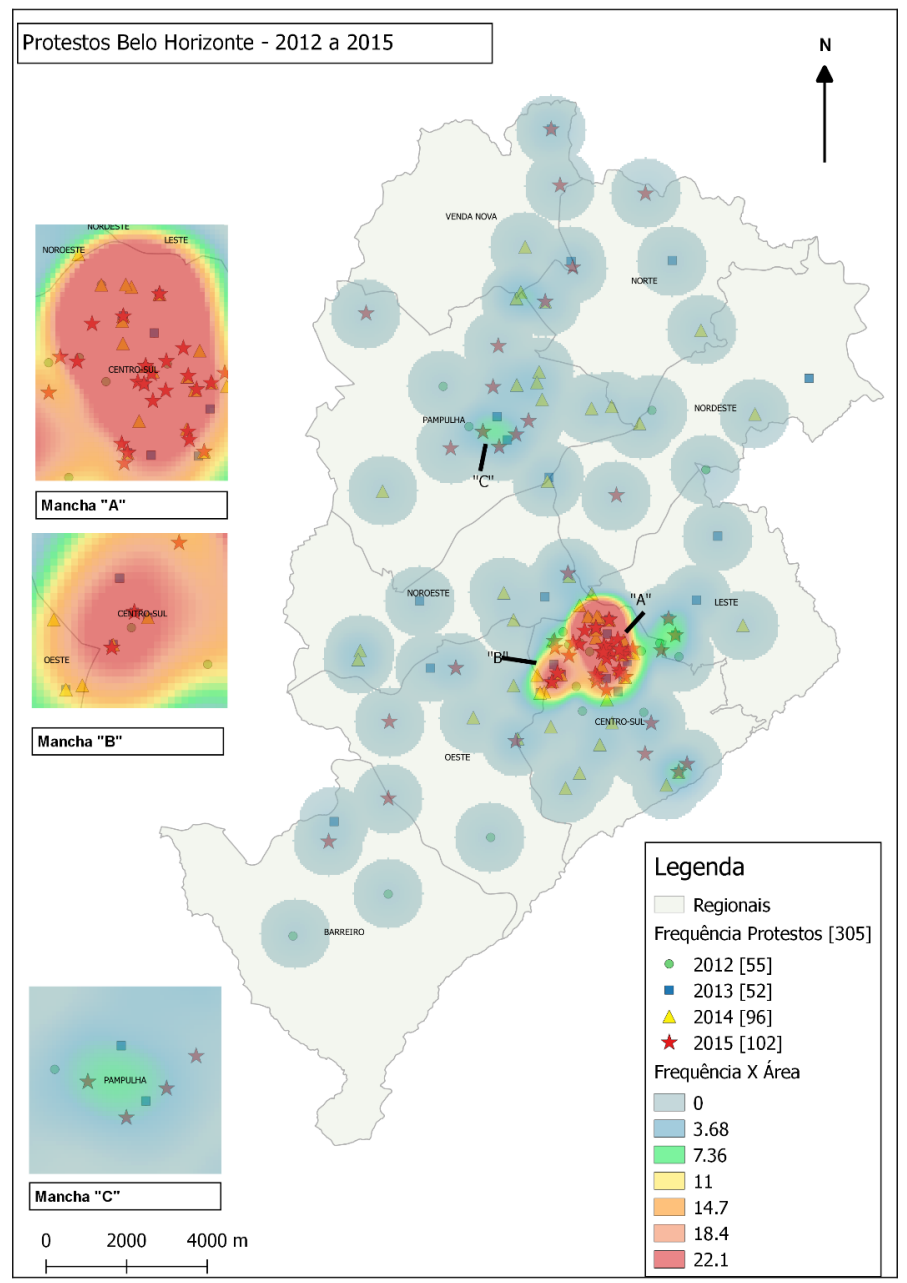

Tabela 4. Grupos que protestam por mobilidade e sua relação com a agenda de protesto Fonte: Elaboração própria a partir dos dados coletados no periódico "O Tempo". 
A macha "A" (mais de 22 protestos) é a que mais se destaca no mapa produzido. Esta demonstra a existência de um "circuito" frequentemente mobilizado para realização de protestos na área mais central da cidade. Esta é composta pela "Praça da Estação" (local em que se encontra a estação central de metrô), a "Praça Sete de Setembro" e também a "Avenida Afonso Pena", principalmente na área próxima à sede da prefeitura municipal.

A mancha "B" é a segunda de maior destaque. Esta compreende o circuito "Praça da Liberdade" e "Praça da Assembleia", sendo este último o local em que se encontra a sede do poder legislativo da cidade e antiga sede do governo estadual, que se mudou para a região metropolitana da cidade em 2010. Mesmo que esta área possua uma intersecção com a anteriormente descrita, verifica-se uma preferência de uso do circuito anterior nos protestos analisados.

Por fim, percebe-se a emergência de uma nova mancha "C" com intensidade relevante (entre 7 e 11 eventos), principalmente a partir de 2015. Sua localidade encontra-se na "Avenida Antônio Carlos", principal via de acesso por veículos à Universidade Federal de Minas, recebendo, portanto, um intenso fluxo de jovens todos os dias.

De forma breve, constata-se que os grupos protagonistas de protestos e manifestações neste contexto possuem uma maior propensão a significar as áreas mais centrais da cidade como um espaço político. Podemos inferir que esta situação se sustenta pelo valor estratégico do uso destes os espaços de mobilidade para garantir a visibilidade dos protestos e repercussão nas instituições politicas (local da sede da prefeitura) e menor custo de encontro para os agentes devido a ampla oferta de transporte público nesta região. Não deve ser descartada também, como dito por Harvey (1980), a influência da importância simbólica dos locais para os agentes.

Posteriormente, procuramos identificar se os protestos de Belo Horizonte possuem uma maior tendência em ocorrerem em espaços de circulação de veículos (ruas ou avenidas), outros espaços públicos (praças, calçadas ou em frente a prédios públicos) ou 
através da ocupação interna de edifícios e prédios. Como resultado, foi possivel constatar que a maior parte dos protestos da cidade utilizam praças ou calçadas em frente a prédios públicos, muitas vezes onde se encontram as sedes dos grupos desafiados pelo protesto (54\%). Não obstante, utilizar os espaços de circulação de automóveis (vias de mobilidade) também é um repertório estratégico para performance das manifestações (40\%), demonstrando como a ocupação de vias públicas e a interrupção do fluxo de veículos na cidade é uma estratégia importante no repertório dos grupos de protesto de Belo Horizonte.

Quando realizamos a mesma análise através da divisão dos dados segundo a motivação dos protestos (agenda da mobilidade urbana ou não), verificamos uma maior tendência na ocupação das vias de mobilidade (66,7\%). Essa tendência é interessante, pois atesta que na busca por gerar visibilidade aos problemas que envolvem a mobilidade urbana, interromper o fluxo de veículos para atrair atenção da população e dos próprios agentes desafiados pelos protestos parece ser um repertório fundamental:

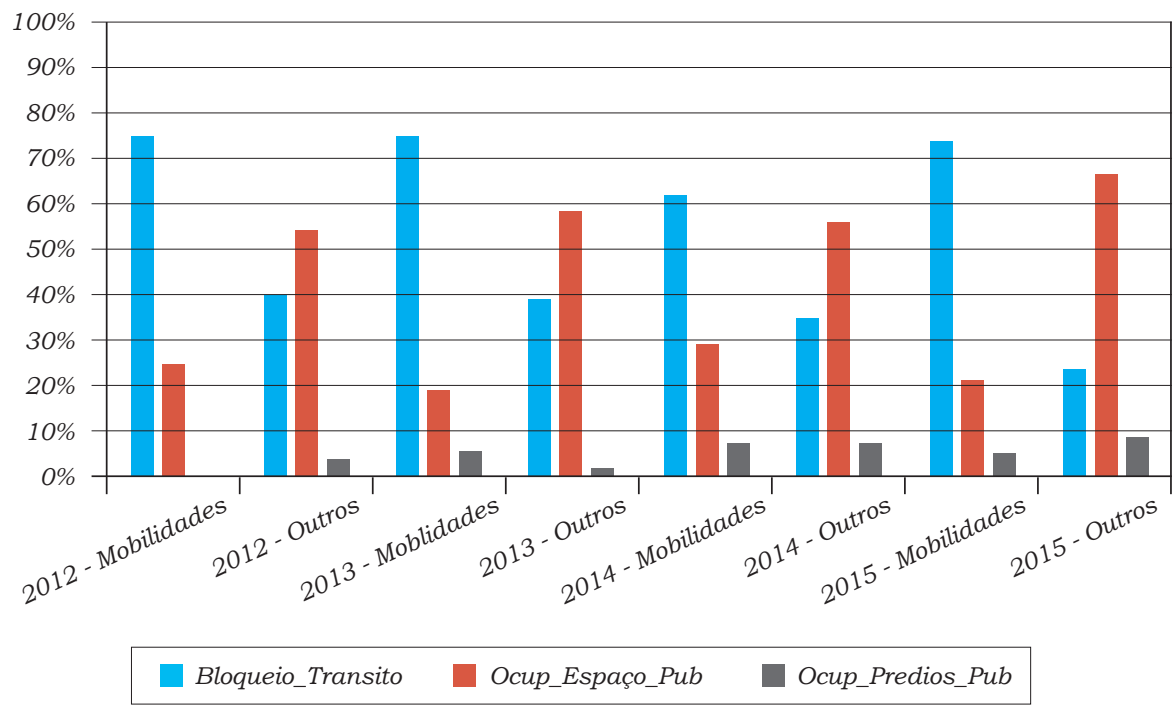

Tabela 5. Espaços públicos em performances de protesto segundo motivação Fonte: Elaboração própria a partir dos dados coletados no periódico "O Tempo". 
Outra variável que procuramos medir foi a movimentação dos manifestantes nos protestos noticiados. Para além do próprio ato de caminhar em passeata, repertório utilizado em larga escala nas manifestações analisadas (noticiado em $28 \%$ dos protestos), é interessante ressaltar que diversas manifestações utilizaram veículos de transporte como complemento performático na cena pública. Essa relação é ainda mais expressiva quando o tema do protesto é a mobilidade urbana: utilizar o próprio automóvel para visibilizar a luta por melhores condições de trabalho e salários motoristas de taxi ("Taxistas protestam", 2015) ou representantes de centros de formação de condutores ("Donos de autoescolas", 2014), por exemplo- ou pela expansão na infraestrutura de mobilidade da cidade -ciclistas ("Ciclistas se reúnem", 2012)-demonstra como identidade, mobilidade e política são categorias que se apresentam lado-a-lado na cena pública. Os dados estão representados abaixo (tabela 6).

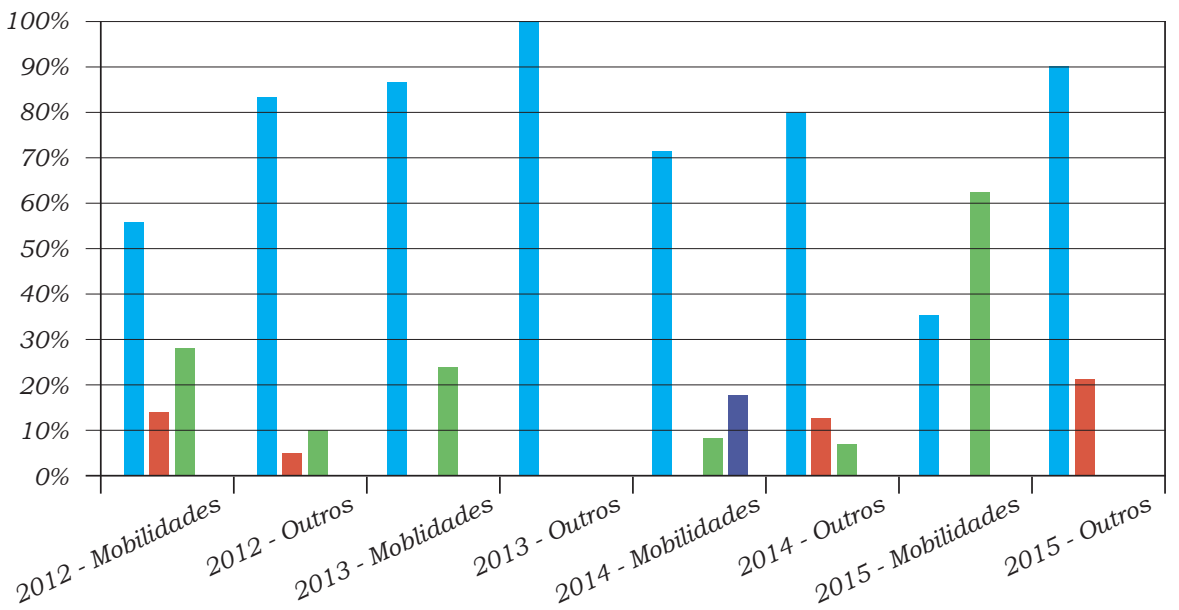

Passeata_Caminhar Carros_Som Carreata

Cicleata

Tabela 6. Performances móveis conforme motivação dos protestos

Fonte: Elaboração própria a partir dos dados coletados no periódico "O Tempo". 
Também foram avaliados os efeitos e impactos que os protestos de Belo Horizonte produziram nos espaços de mobilidade da cidade. Verifica-se, dentre as notícias que descreveram os efeitos dos protestos de Belo Horizonte, que $61 \%$ impactaram de alguma forma o trânsito da cidade, em alguns casos causando lentidão em diversas avenidas importantes da cidade ("Greves param trânsito", 2014; "Trânsito da Centro-Sul para", 2014). Este dado corrobora a conclusão de que interromper as vias de mobilidade urbana da cidade é um dos repertórios mais acionados para garantir visibilidade a protestos, demonstrando a grande importância simbólica e prática dos espaços de mobilidade na construção de um campo político de contestação. Destacam-se, dentre outros efeitos, tumultos, brigas e conflitos com a polícia (11\%) ("Violência em ato", 2015) e interrupção de atividades de trabalhadores em áreas de manifestações coletivas (7\%) (“Capital para em manhã de caos”, 2015).

\section{Considerações finais}

Neste artigo, foi verificada a intensidade e composição da agenda política de mobilidade urbana nos protestos da cidade de Belo Horizonte, entre os anos de 2012 e 2015. Também procurou-se compreender como dinâmicas de mobilidade urbana se apresentam no repertório e performance de protesto de grupos protestantes.

A partir da análise realizada, pudemos atestar que a agenda política de mobilidade urbana na cidade, apesar de variar segundo oportunidades políticas de um contexto, é uma intensa motivação de confronto e protestos coletivos na cidade. Esta varia segundo interesses, identidades e definições de mobilidade urbana realizadas pelos atores sociais de um contexto, sendo portanto plural, complexa e contextual. Envolve tanto a busca pela redução das tarifas de transporte público como pela qualidade, direito e infraestrutura deste. Também se destacam os conflitos e reivindicações de profissionais que oferecem serviços de transporte público ou particular. Deste modo, podemos verificar como a definição de mobilidade 
urbana, sua importância como ferramenta e identidades dos grupos são essenciais para se compreender sua dimensão política.

Com relação a repertórios e performances de protesto, demonstrou-se que de acordo com a percepção e a performance de grupos de protesto alguns espaços urbanos tem uma maior propensão de serem significados como arenas propícias a contestação política. Estas não se limitam somente a praças e calçadas frente a edifícios e sedes de grupos desafiados, mas também as próprias ruas e avenidas da cidade, demonstrando que os espaços da mobilidade são também espaços de mobilização política.

Não obstante, explicitou-se que não somente o movimento de pessoas é relevante para realização de protestos políticos, mas que veículos e outras ferramentas de transporte participam na composição das performances políticas analisadas. Por fim, que a estratégia de interrupção de vias de mobilidade em atos politicos coletivos é um repertório constantemente acionado na busca pela visibilidade e publicitação dos mesmos.

A sequência deste estudo buscará comparar as variáveis observadas na cidade de Belo Horizonte com outros dados colhidos na cidade do Rio de Janeiro. Através de um contraste, procuraremos identificar tanto novidades como diferenças entre agendas, agentes, performances e espacialidades de forma a realizar novas contribuições a esta área de estudos.

\section{Referências}

Belo Horizonte tem 20 mil nas ruas e confronto com a PM. (2013, junio 18). Jornal O Tempo.

Butler, J. (2015). Notes Toward a Performative Theory of Assembly. Cambridge - London: Harvard University Press. 
Capital para em manhã de caos. (2015, mayo 30). Jornal O Tempo.

Cardoso, G. y Fátima, B. Di. (2013). Movimento em rede e protestos no brasil qual gigante acordou ? Movements through net and protests in brazil which giant woke up? Dossiê Mídia, Intelectuais E Politica, 16(2), 143-176. Recuperado de http://revistas.ufrj.br/index.php/eco_pos/article/viewFile/1182/1123

Certeau, M. de. (1998). A invenção do cotidiano: artes de fazer. Petrópolis: Vozes.

Ciclistas organizam protesto. (2014, julio 12). Jornal O Tempo.

Ciclistas se reúnem em protestos pelo país. (2012, marzo 7). Jornal O Tempo.

Cresswell, T. (2006). On the move: mobilities in the modern western world. New York: Routledge.

Cresswell, T. (2011). Mobilities I: Catching up. Progress in Human Geography, (35), 550-558.

Donos de autoescolas protestam em carreata. (2014, enero 4). Jornal O Tempo.

Estudantes protestam contra reajuste. (2012, diciembre 14). Jornal O Tempo.

Gohn, M. da G. (2013). Sociedade civil no Brasil: movimentos sociais e ONGS. Revista Meta: Avaliação, 5(14), 238-253.

Greves param trânsito de BH. (2014, mayo 13). Jornal O Tempo.

Harvey, D. (1980). A Justiça Social e a Cidade (Trad. A. Corrêa da Silva). São Paulo: Hucitec.

Jovens voltam as ruas do pais. (2014, enero 26). Jornal O Tempo.

Judensnaider, E., Lima, L., Pomar, M. y Ortellado, P. (2013). Vinte Centavos: a luta contra o aumento. São Paulo: Veneta. 
Kaufmann, V. (2014). Mobility as a Tool for Sociology. Sociologica, (1). Recuperado de http://www.sociologica.mulino.it/journal/article/index/ Article/Journal:ARTICLE:736. https://doi.org/ 10238377046

Lefebvre, H. (2008). Espaço e política. Belo Horizonte: EdUFMG.

Lévy, J. (2001). Os novos espaços da mobilidade. Geographia, (6), 1-11.

Lorimer, H. (2011). Walking: New forms and spaces for studies of pedestrianism. En F. Ashgate (Ed.), Geographies of Mobilities: Practices, Spaces, Subjects (pp. 19-34). Farnham: Cresswell T and Merriman P.

Mais violência e menos diálogo. (2015, agosto 29). Jornal O Tempo.

Manifestação pacífica termina com explosão de violência. (2014, junio 13). Jornal O Tempo.

Manifestação também na capital. (2015, enero 8). Jornal O Tempo.

Massey, D. (2008). Pelo espaço: uma nova politica da espacialidade. Rio de Janeiro: Bertrand Brasil.

Matos Wunderlich, F. (2008). Walking and rhythmicity: Sensing urban space. Journal of Urban Design, 13(1), 125-139.

Melucci, A. (2001). A invenção do Presente. Rio de Janeiro: Vozes.

Nobre, M. (2013). Imobilismo em movimento. São Paulo: Cia das Letras.

Ônibus parados na segunda. (2012, marzo 10). Jornal O Tempo.

Ortellado, P. (2013). Os protestos de junho entre o processo e o resultado. En E. Judensnaider, L. Luciana, P. Marcelo y O. Pablo (Eds.), Vinte Centavos: a luta contra o aumento (pp. 227-239). São Paulo: Veneta.

Pedro II é fechada, e caos se repete. (2014, junio 11). Jornal O Tempo. 
Praça tomada por insatisfeitos. (2015, agosto 17). Jornal O Tempo.

Protesto. (2015, julio 6). Jornal O Tempo.

Protesto na prefeitura e no metrô. (2014, enero 31). Jornal O Tempo.

Protesto reúne 400 pessoas em Belo Horizonte. (2015, enero 10). Jornal O Tempo.

Ricci, R. y Arley, P. (2004). Nas ruas; a outra politica que emergiu em junho de 2013. Belo Horizonte: Letramento.

Ruas ocupadas por protesto de várias causas. (2013, junio 16). Jornal O Tempo.

Santos, M. (1996). A natureza do espaço: técnica e tempo, razão e emoção. São Paulo: Hucitec.

Sheller, M. y Urry, J. (2006). The new mobilities paradigm. Environment and Planning, (38), 207-226.

Singer, A. (2013). Classes e ideologias cruzadas. Novos Estudos CEBRAP, Novembro, 2(97), 23-40.

Tarrow, S. (2009). O poder em movimento. Rio de Janeiro: Vozes.

Taxistas protestam contra o Uber, e senador defende lei. (2015, noviembre 12). Jornal O Tempo.

Tilly, C. (1995). Cycles of collective action: between moments of madness and the repertoire of contention. En M. Traugott (Ed.), Repertoires and cycles of collective action (pp. 89-116). Durham, NC: Duke University Press.

Touraine, A. (1984). O retorno do actor. Lisboa: I. Piaget.

Touraine, A. (1998). Poderemos Viver Juntos? Iguais e Diferentes. Petrópolis: Vozes. 
Touraine, A. y Khosrokhavar, F. (2004). A Busca de Si: Diálogo sobre o sujeito. Rio de Janeiro: Difel.

Trânsito da Centro-Sul para. (2014, mayo 30). Jornal O Tempo.

Urry, J. (2000). Sociology Beyond Societies: Mobilities for the Twenty-first Century. London: Routledge.

Violência em ato contra a tarifa. (2015, agosto 13). Jornal O Tempo.

\section{Cómo citar este artículo}

Hasz, L. y Nigri, L. (2018). Mobilidades Urbanas, Espaços Públicos e Manifestações Populares: uma análise dos protestos ocorridos na cidade de Belo Horizonte entre 2012 e 2015 . Universitas Humanistica, 85, 235-261. https://doi.org/10.11144/Javeriana.uh85.muep 